\title{
On Social Demands for Tennis Talents and Ability Cultivation of Tennis Talents in Universities

\author{
Xin-yu ZHANG*, Ji-hua CHEN
}

\author{
Physical Culture Institute, Leshan Normal University, Leshan, Sichuan, China
} \\ ${ }^{*}$ Corresponding author
}

Keywords: Social Demands; Tennis Talents; Ability Cultivation.

\begin{abstract}
The cultivation of tennis talents in universities must conform to social demands. Researches have shown that more tennis coaches, training partners, referees, competition organizing and arranging staff are increasingly required due to the rapid development of tennis sport. In order to cultivate tennis talents in universities to meet the needs of society, this paper explores the cultivation objectives, course contents, students' practical abilities and course evaluation.
\end{abstract}

\section{Introduction}

In recent years, the demands for tennis talents in the society tend to be diverse with the rapid development of the national economy and the popularization of the tennis sport, which means the basic ability training is particularly important under such circumstances in where more tennis talents are needed. Therefore, the current study, with the social demands for tennis talents as a point of penetration, has presented feasible ways of cultivation in defining the objectives of tennis talents cultivation in universities, adjusting the course contents, improving the practical abilities of students, integrating the courses, competitions and certificates and enhancing the evaluation on basic abilities based on an investigation into social needs for tennis talents, which is of great theoretical significance and practical value in improving the students' competitiveness in future career and providing better and broader employment prospects.

\section{Social Demands for Tennis Talents}

\subsection{The operation of amateur clubs requires coaches and training partners who are able to perform at a higher level}

With the rapid development of economy, more and more people pay attention to their mental and physical health and the physical fitness idea of "Pay For Health" is generally accepted. Tennis has attracted more and more participants because it is attractive and entertaining, and good for body building. It can be played by men and women of all ages, young and old. However, the extremely complex skills involved in tennis sport make some participants blocked out. For example, some beginners may suffer from injuries due to unstandardized skills and lack in understanding of rules, thus losing their patience and interests. So, professional tennis training partners are needed to meet this fitness demands. According to a survey, the tennis training partners in the society at present mainly consist of college students majoring in tennis sport, retired professional athletes and other persons with practical experience. If the tennis training partners want to be completive, they must do well in partner training, injury prevention and scientific fitness guidance which are not available to many training partners. As the number of tennis enthusiasts increases, more tennis training partners are needed. Therefore, we should seize this opportunity to cultivate professional tennis training partners.

\subsection{Tennis coaches}

As a new sport, tennis is developing rapidly in China. Especially, the operation of commercial tennis clubs plays a great role in the popularization and development of tennis in China. In recent years, tennis stadiums and clubs of various levels and types have mushroomed all over the country. 
The establishment of those stadiums and clubs brings opportunities for the tennis major in Chinese universities on the one hand and poses a challenge on the other hand. For instance, many employment chances are provided because tennis stadiums and clubs require professional tennis coaches. But professional tennis coaches must be competent in tennis competition, education and tactical instruction. At present, the tennis coaches in clubs mainly consist of college students majoring in tennis and some retired tennis players. The college students have the teaching ability but they lack contest participation experience, while the retired tennis players have rich contest experience but they can't do well in scientific training, scientific research and management. The overall comprehensive quality of tennis coaches is one of the main factors for the healthy and rapid development of tennis clubs. Therefore, with the popularity of tennis clubs, the society is in urgent need of a large number of tennis talents with good comprehensive abilities such as tennis competitive ability and coaching ability.

\subsection{Referees}

The quantity and quality of tennis referees, as the main component of the tennis sport, can affect the development of tennis. At present, the referee's work in China's amateur tennis competitions is mainly done by those who have stable jobs but have a little knowledge of tennis judging. Those people are not professional enough and can't deliver accurate judgment. Therefore, the justice and equity of those competitions can't be ensured and the enthusiasm of the public for tennis and the development of tennis sport will be influenced. As people are increasingly interested in tennis sport, a large number of tennis competitions, large and small, have been held in China, such as various national amateur competitions, provincial competitions, college competitions and some community competitions. The more domestic competitions are held, the greater the demands for referees are. Therefore, tennis competitions at various levels require a large number of professional referees.

\subsection{Competition organization and arrangement}

Competition organization and arrangement is a process of organizing, directing, controlling and adjusting the competition work purposefully, and is the guarantee of the smooth running of the competition. Competition organizers need to complete such work in advance as the inspection of hardware equipment, providing of related services, coordination between works, capacity building for giving professional services and establishment of an emergency response mechanism. Therefore, the planning, organization and operation of tennis competitions require knowledge about the organization and arrangement. What's more, professional staff with good professional quality and service awareness should do well in the coordination, connection and emergency work, so as to ensure a standardized professional tennis tournament. Currently, amateur tennis competitions are emerging one after another in China with a constantly expanding scale. However, in the process of hosting those tennis competitions, there is not enough professional staff to do relevant professional and technical work including the organization, arrangement, management and service providing of tennis matches.

\subsection{Operation of tennis clubs and lack of management personnel}

Most of the management personnel in tennis clubs enjoy a higher cultural level. Some of them are sports professionals. They don't have good comprehensive business quality, because they lack knowledge of economic management and law due to the influence of course offering in colleges. Although some of operation mangers are specialized in business management or economic administration, they are lacking in professional knowledge about physical fitness. The remaining managers are neither sports professionals nor talented managers and they know little about sports and management.

Talents are important in the operation of tennis clubs, especially those with the capability to do well in operation and management. However, most operation managers are interest-driven and they are not professionals. 


\section{Ability Cultivation}

\subsection{Defining the objectives of talent cultivation}

The objectives of talent cultivation in universities not only directly affect the depth and breadth of students' knowledge and skills, but also affect students' ability to adapt to social needs. The traditional idea that mastering skills is the most important can't meet the needs of the current social development and is not conducive to the development of tennis teaching. Therefore, the goal orientation of talent cultivation in universities should be consistent with social demands for tennis talents. Based on the social demands, we should aim to cultivate compound talents such as tennis coaches, tennis fitness instructors, operators and managers in tennis clubs, tennis referees and tennis teachers of various levels who are competent to teach, train, instruct, manage, organize and do scientific researches, in order to provide talents of proper types and structures for the society.

\subsection{Offering scientific and time-efficient tennis courses}

The course contents are closely associated with talent cultivation and the quality and specification of talent cultivation directly depend on colorful teaching contents of various forms. In order to meet the social demands for tennis talents, it is necessary to offer scientific and time-efficient tennis courses after defining the cultivation objectives so as to enhance the quality of talent cultivation. Based on Table 1, students should be taught some basic tennis skills in the terms $1-2$, basic tennis tactics in the terms $2-3$, tennis competitions and basic knowledge in the whole 8 terms, referee's knowledge in the terms 2-5, competition organization and arrangement in the term 6 and scientific research in the terms 6-7. The teaching should be progressive and continuous and theory teaching and practice should be integrated.

Table 1. Allocation of Teaching Contents

\begin{tabular}{lllllllll}
\hline Teaching Content & Term 1 & Term 2 & Term 3 & Term 4 & Term 5 & Term 6 & Term 7 & Term \\
\hline Basic Skills & $\vee$ & $\vee$ & & & & & & \\
Basic Tactics & & $\vee$ & $\vee$ & & & & & \\
Competitions & $\vee$ & $\vee$ & $\vee$ & $\vee$ & $\vee$ & $\vee$ & $\vee$ & $\vee$ \\
Theoretical Knowledge & $\vee$ & $\vee$ & $\vee$ & $\vee$ & $\vee$ & $\vee$ & $\vee$ & $\vee$ \\
Referee's Knowledge & & $\vee$ & $\vee$ & $\vee$ & $\vee$ & & & \\
Organization and & & $\vee$ & $\vee$ & $\vee$ & $\vee$ & \\
Arrangement & & & & & $\vee$ & $\vee$ \\
Scientific Research & & & & & & $\vee$ & \\
\hline
\end{tabular}

3.3 Strengthening the cultivation of practical ability

Table 2. Practical Methods for Development of Basic Tennis Abilities

\begin{tabular}{ll}
\hline Basic Abilities & Practical Methods \\
\hline $\begin{array}{l}\text { Tennis coaching, partner } \\
\text { training and teaching }\end{array}$ & $\begin{array}{l}\text { In class: grouping can be adopted to conduct coaching, partner } \\
\text { training and teaching practices; out of class: providing coaching, } \\
\text { partner training and teaching services for those tennis enthusiasts } \\
\text { not majoring in tennis. }\end{array}$ \\
$\begin{array}{l}\text { Tennis judging and } \\
\text { competition organizing and } \\
\text { arranging abilities }\end{array}$ & $\begin{array}{l}\text { off campus and serve as referees by themselves. } \\
\text { Operating and managing } \\
\text { abilities in tennis clubs }\end{array}$
\end{tabular}

Combined with social demands for tennis talents, the basic abilities for tennis include those in the aspects of tennis coaching, partner training, judging, competition organizing and arranging, teaching and operating and managing of tennis clubs. For development of coaching, partner training 
and teaching abilities, grouping can be adopted to conduct coaching, partner training and teaching practices in class and those students not majoring in tennis can be chosen as objects to receive free coaching, partner training and teaching services out of class. For development of judging and competition organizing and arranging abilities, tennis matches on and off campus can be conducted in where students can serve as referees, and they can be organized and arranged by students themselves. For development of operating and managing abilities in tennis clubs, students should be encouraged to go on field trips to various clubs on the weekends or on holidays. During the development of practical abilities, teachers should follow up in the whole process, guiding actively, finding problems and solving them in time.

\subsection{Introduction to professional qualification authentication}

At present, the system of position certificates and professional qualification certificates has been implemented in most industries in China. Especially, some special positions require relevant personnel to have corresponding qualification certificates, such as tennis coaches and tennis referees. Referring to the talents training mode of integrating courses, matches and certificates in Physical Culture Institute, Leshan Normal University, students should be taught basic knowledge, skills and abilities involved in the major in class, and encouraged to take part in various matches on and off campus. On the one hand, students can locate and make up the deficiencies in matches which can be a feedback on the teaching. On the other hand, students can obtain related certificates through participation in those matches, in favor of job hunting after graduation. In addition, the "certificates" here also include professional qualification certificates which can be introduced to schools and can offset credits. For example, if a student from the physical culture institute gets corresponding certificates in such programs as the swimming, aerobics and tennis, he can work in the corresponding post. Therefore, the introduction of professional qualification authentication can urge students to make career plans and expand the channels for students' employment while bringing economic benefits to schools.

\subsection{Broadening the scope of ability evaluation}

The content of the ability evaluation should be determined according to the social demands for tennis talents. The traditional teaching evaluation is mainly based on technical evaluation while the proportion of students' basic ability evaluation is much too small. In order to meet social needs, the scope of teaching evaluation requires expanding and deepening, and the proportion of evaluation on students' ability should be increased.

The evaluation on basic theoretical knowledge, technique and tactics can be conducted through a written test, oral test, technical assessment and stage assessment, and the ability evaluation should be integrated into the current examination system.

Table 3. Indicators for Evaluation on Basic Abilities

\begin{tabular}{ll}
\hline Basic Abilities & \multicolumn{1}{c}{ Scope of Evaluation } \\
\hline Coaching & $\begin{array}{l}\text { Technical and tactical level, theoretical level, competition performance, ability } \\
\text { to detect and correct wrong movements, ability to train and instruct, ability to } \\
\text { guide athletes in competition, ability to prevent injuries, ability to deal with } \\
\text { emergencies, ability to coordinate, etc. }\end{array}$ \\
Partner training & $\begin{array}{l}\text { Ability to detect and correct wrong movements, ability to give guidance over } \\
\text { fitness, ability to prevent injuries, ability to feed a ball, ability to communicate, } \\
\text { ability to explain theories, etc. }\end{array}$ \\
Judging & $\begin{array}{l}\text { Ability to fill in a score sheet, ability to handle a special ball, ability to announce } \\
\text { scores, ability to control a match, etc. }\end{array}$ \\
Organizing and & Ability to prepare before competition, ability to make rules, ability to arrange \\
arranging & competitions, ability to serve, ability to solve accidental events, etc.
\end{tabular}




\section{Conclusion}

According to the social demands for tennis talents, there is a serious shortage of tennis coaches, training partners, referees and organization and arrangement personnel of tennis competitions, which not only provides students with a lot of employment opportunities but also specifies the direction of talent cultivation for us. The cultivation of tennis talents should be closely combined with social development and market demands, attach importance to ability cultivation and social transformation, and speed up the cultivation of compound tennis talents.

\section{References}

[1] Liu Xiangyang. Research on the Courses' Setting Up for the Sports Training Specialty in P.E. Institutes in China [D]. Master's Thesis in Southwest University, 2006: 22-25.

[2] Liang Gaoliang. Teaching Innovation of Tennis Training Courses for Sports Training Major Oriented to the Needs of Society [J]. Journal of Shandong Institute of Physical Education and Sports, 2011, 27 (10): 82-87.

[3] Yao Aiqi. Educational Objective and Course Setting Objective for Tennis Major in Wuhan Sports University [D]. Master's Thesis in Wuhan Sports University, 2014.

[4] Cheng Jie, Lu Yinghao, Lu Shubing. Construction and Practice of Tennis Courses in Common Colleges and Universities in China [J]. Journal of Beijing Sport University, 2007, 30 (12): 1700$1701,1706$. 